\title{
Influence of curcumin supplementation on metabolic and lipid parameters of people living with HIV/AIDS: a randomized controlled trial
}

Tatiane Andreza Lima Silva', Danielle Coutinho Medeiros², Gidyenne Christine Bandeira Silva Medeiros ${ }^{3}$, Rafaela Catherine Silva Cunha Medeiros², Juliany de Souza Araújo², Jason Azevedo Medeiros², Marcela Abbott Galvao Ururahy ${ }^{4}$, Ronaldo Vagner Thomatieli Santos ${ }^{5}$, Radames Maciel Vitor Medeiros ${ }^{6}$, Lucia Leite-Lais ${ }^{3 *}$ (D) and Paulo Moreira Silva Dantas ${ }^{2}$

\begin{abstract}
Background: Scientific studies have shown that the potential therapeutic efficacy of curcumin in several diseases is due to its potent antioxidant and anti-inflammatory properties. Consequently, curcumin supplementation seems to be a valuable alternative for HIV-infected individuals. The aim of this study is to evaluate the influence of curcumin supplementation on substrate oxidation at rest, body composition, and the lipid profile of physically active people living with HIV/AIDS under antiretroviral therapy.

Methods: This double-blind, crossover, randomized clinical trial was comprised of 20 subjects divided into experimental (EG) and control (CG) groups, receiving $1000 \mathrm{mg}$ curcumin/day and placebo, respectively, during a 30-day period. Substrate oxidation at rest was assessed by indirect calorimetry, body composition was measured by dual-energy $x$-ray absorptiometry, and the lipid profile was evaluated by blood tests. Data analysis was performed by independent samples and paired t-tests to compare the differences between groups and times. A $p$-value $<0.05$ was accepted as significant.

Results: There were no differences between groups regarding substrate oxidation at rest or body composition. However, serum triglyceride levels were increased after curcumin supplementation (182 vs. $219 \mathrm{mg} / \mathrm{dL} ; p=0.004$ ).

Conclusion: Curcumin supplementation promoted the elevation of serum triglyceride levels in HIV-infected subjects. Further studies with a larger sample cohort, different curcumin doses, and longer intervention times are needed to validate current observations. In addition, the influence of physical activity, dietary intake, and genetic polymorphisms must be considered in future studies to better understand the impact of curcumin supplementation on the lipid profile of people living with HIV/AIDS under antiretroviral therapy.
\end{abstract}

Keywords: Curcumin, Dyslipidemia, HIV/Aids

\footnotetext{
* Correspondence: ludl10@hotmail.com

${ }^{3}$ Department of Nutrition, Federal University of Rio Grande do Norte, Campus

Universitario, Lagoa Nova, Natal, RN 59078-900, Brazil

Full list of author information is available at the end of the article
}

(c) The Author(s). 2019 Open Access This article is distributed under the terms of the Creative Commons Attribution 4.0 International License (http://creativecommons.org/licenses/by/4.0/), which permits unrestricted use, distribution, and reproduction in any medium, provided you give appropriate credit to the original author(s) and the source, provide a link to the Creative Commons license, and indicate if changes were made. The Creative Commons Public Domain Dedication waiver (http://creativecommons.org/publicdomain/zero/1.0/) applies to the data made available in this article, unless otherwise stated. 


\section{Background}

Antiretroviral therapy (ART) is able to dramatically increase the survival and quality of life in people living with HIV/AIDS. However, these advantages are often associated with metabolic alterations and risk of cardiovascular diseases, which are difficult to manage [1].

Strategies to reduce cardiovascular risk should be prioritized in the health care of people using ART. In most cases, lifestyle changes are not enough to reverse the atherogenic dyslipidemia observed in this population. Besides healthy diet, regular physical activity, smoking cessation and alcohol abstinence, the use of conventional lipid lowering drugs are needed [1-3]. Nevertheless, prescription of lipid lowering drugs in this population requires strict clinical monitoring due to its possible pharmacokinetic interactions with antiretroviral drugs [4]. Moreover, the concomitant use of fibrates and statins increases the risk of skeletal muscle toxicity and rhabdomyolysis [5-7].

Bioactive compounds naturally present in foods, which are able to modulate serum lipid levels in favor of a less atherogenic profile, may have a special role in this population. Curcumin, a polyphenol extracted from Curcuma longa L. commonly known as turmeric, has been highlighted due to its effects on many biological pathways and it is considered safe [8]. Despite the challenges of curcumin action due to its low solubility and poor bioavailability, its antiviral, anti-inflammatory, and antioxidant properties have pointed to curcumin as a promising bioactive compound with a positive effect on the treatment of HIV infection and AIDS [9, 10], inflammatory diseases [11], cancer [12], diabetes [13], and metabolic syndrome [14]. Curcumin acts on molecular targets associated with intestinal cholesterol absorption and regulation of lowdensity lipoprotein (LDL) receptors and it may be helpful to improve the lipid profile [15].

The inflammatory process and oxidative stress caused by the HIV virus and ART lead to metabolic alterations, such as dyslipidemia [16], lipodystrophy [17], and insulin resistance [18], which increase the risk of cardiovascular events. Therefore, curcumin supplementation as a nondrug strategy seems to be a valuable alternative for HIVinfected people under ART. Thus, the aim of this study was to evaluate the effect of curcumin supplementation on substrate oxidation at rest, body composition, and lipid profile of people living with HIV/AIDS and under ART.

\section{Methods}

\section{Study design, ethical aspects, and supplementation}

This study was a double-blind, crossover, randomized clinical trial, conducted according to the Declaration of Helsinki, between September and December 2017. It was reviewed and approved by the Human Research Ethics Committee of the Federal University of Rio
Grande do Norte, Brazil (CAAE 42950214.7.0000.5537), and was registered in Clinical Trials (NCT03141918), available at https://clinicaltrials.gov/ct2/show/NCT03141 918. Written consent was obtained from all participants. Subjects were randomized 1:1 to the experimental group (EG) or control group (CG), supplemented with curcumin or placebo, respectively.

The randomization was performed by an independent researcher using the Research Randomizer, a free online tool. He kept the original random allocation sequences in an inaccessible location and worked with a copy. Participants received identification codes which were revealed at the end of the study. The curcumin or placebo supplementation was distributed by the independent researcher and both capsules were similar in color and size. The study was double blind, meaning that neither participants nor investigators responsible for conducting the assessments were aware of the allocated arm until the statistical analysis was performed.

The EG and the CG received $1000 \mathrm{mg}$ curcumin/day for 30 days (BioMor ${ }^{\oplus}$ Curcumin) and $1000 \mathrm{mg}$ microcrystalline cellulose (placebo), respectively, divided into two capsules of $500 \mathrm{mg}$ each, which were taken with water two hours after breakfast and two hours after lunch. After 30 days of supplementation, a washout period of 12 days was implemented. For logistical issues, this period was longer than the washout period recommended in clinical trials with curcumin supplementation, which is 7 days [19]. Afterwards, the groups were switched to follow the crossover design. Full assessments were performed at four different intervals (Fig. 1).

\section{Participants}

This study was carried out with people living with HIV/ AIDS of both sexes, members of the Viver+ program, offered by the Federal University of Rio Grande do Norte (UFRN). This program offers nutritional advice and exercise guidance to this population. The sampling method adopted was non-probability for convenience. The data were collected at the Physical Education Department at UFRN in Natal, Brazil.

The participants of this study were previously enrolled in a 6-month exercise plan, prescribed according to the American College of Sports Medicine [20]. The exercise plan consisted of a combination of aerobic and resistance training, 3 times/week on nonconsecutive days, with moderate intensity, for $50 \mathrm{~min}$ ( $10 \mathrm{~min}$ of aerobic training and $40 \mathrm{~min}$ of resistance training). At baseline, participants presented a mean VO2 peak of $33.7 \mathrm{~mL} / \mathrm{kg} /$ min and were physically active according to the International Physical Activity Questionnaire classification [21]. Throughout the study, participants were advised not to change their lifestyle, including diet and physical activity. Thus, during the study all participants 


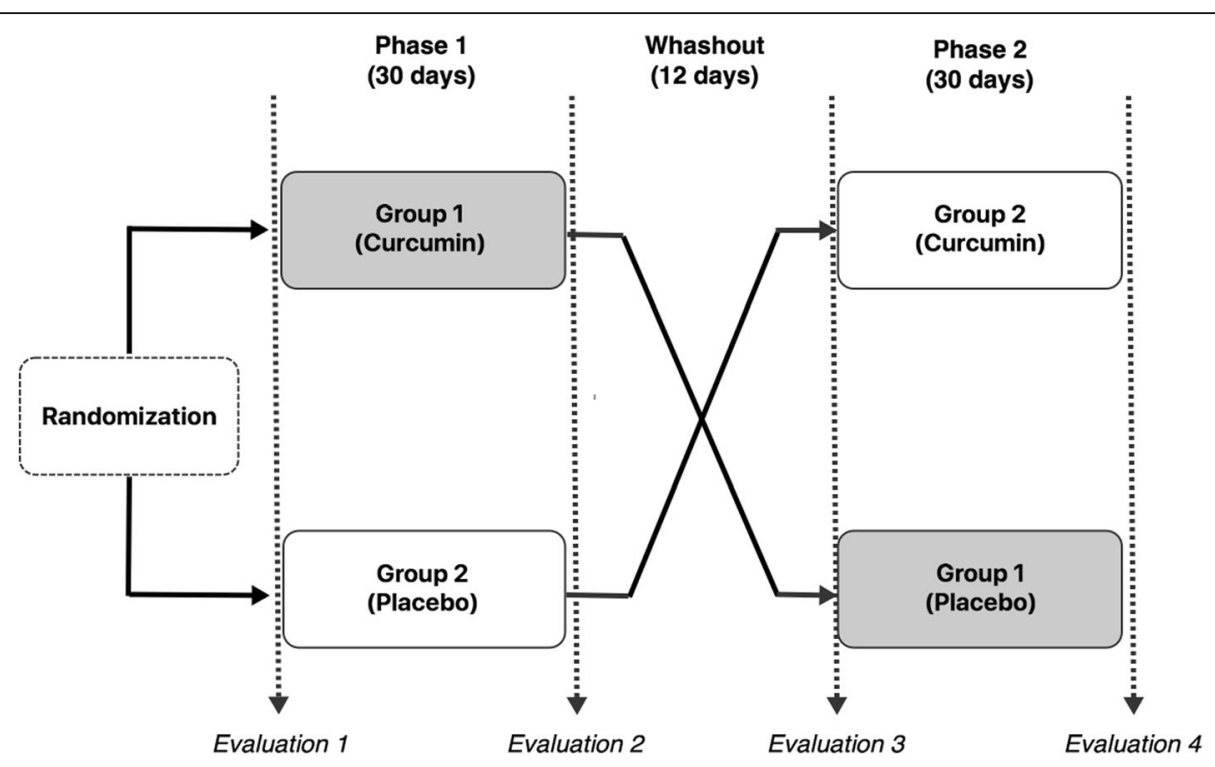

Fig. 1 Study Design. Legend: This figure shows the formulation of the trial, including the randomization process, phase 1, washout, and phase 2 periods. Also, it shows the groups 1 and 2 as experimental group (EG) and control group (CG), respectively, and their cross-over during the follow up. In addition, four reference points for evaluations 1-4 are pointed out. Each evaluation was comprised by full assessment, including anamnesis, 24-h dietary recall, indirect calorimetry, dual-energy X-ray absorptiometry, blood collection, and biochemical analysis

continued to follow the exercise plan, which was monitored by Physical Education professionals through the Borg [22] and OMNI-RES [23] subjective perception of exertion scales for aerobic and resistance training, respectively.

Inclusion criteria were subjects over 18 years of age who had been using ART for at least 18 months, sufficient time to be vulnerable to the side effects of the treatment. Exclusion criteria to avoid bias were subjects using Curcuma longa L., taking curcumin or thermogenic supplements, with acute infection, pregnant individuals, and exercise training attendance below $75 \%$. Information was registered on the evaluation form (Additional file 1).

\section{Study procedures \\ Anamnesis}

A semi-structure questionnaire was developed for this study to collect personal, lifestyle, and clinical data, including the time of HIV diagnosis, time taking ART, combination of medications used, and the presence of comorbidities (see Additional file 1).

\section{Dietary intake}

Dietary intake was evaluated as a control variable, since the participants were advised not to change their eating habits during the study. For this, food intake was investigated by trained registered dietitians through 24-h recalls, according to the literature recommendations [24]. Four 24-h recalls were collected for each patient during evaluations 1-4 (Fig. 1). A picture book with food portions and measurements was used to estimate portion sizes. Dietary energy, macronutrients, cholesterol, and dietary fiber were measured applying Diet Easy ${ }^{\circ}$ software. Food items that were not found in the software's databank were added based on the nutrition facts labels.

In addition, participants filled out a questionnaire, called Food Consumption Markers, developed by the Brazilian Ministry of Health [25]. The purpose of this tool was to check the weekly frequency of consumption of 10 food groups organized according to their level of food processing as well as sources of specific nutrients, such as sugar, saturated fat, and fiber. Groups 1 to 5 comprise unprocessed or minimally processed foods, while groups 6 to 10 comprise processed or ultra-processed foods. The analysis of the Food Consumption Markers collected was performed based on the following equation: Score $=1 / 7 \mathrm{x}$ consumption frequency, adapted from Fornés et al. [26]. The results were expressed as percentages.

\section{Substrate oxidation at rest}

Evaluation of the substrate oxidation at rest was performed by indirect calorimetry (Cortex Metalyzer 3B, Biophysik, Leipzig, Germany). Subjects were instructed to sleep approximately $8 \mathrm{~h}$ the night before, perform a 12-h fast, not exercise within $48 \mathrm{~h}$ prior to the evaluation, and not to consume caffeine or alcohol-containing beverages within $24 \mathrm{~h}$ prior to evaluation.

The indirect calorimetry procedure occurred between 7:00 am and 8:00 pm. The laboratory had low-light 
conditions, controlled noise levels, temperature between 23 and $25{ }^{\circ} \mathrm{C}$, and relative humidity between 40 and $60 \%$. The participants remained comfortable in a supine position for $30 \mathrm{~min}$, remaining awake and immobile for the last $30 \mathrm{~min}$.

\section{Body composition}

Body composition was measured by indirect dual energy radiological absorptiometry (DXA) (GE, Prodigy Advance model, GE Lunar software, Madison, USA). The percentages of total fat and fat per segment were quantified.

\section{Lipid profile}

After an overnight fast, $5-10 \mathrm{~mL}$ blood samples were collected from the antecubital vein of participants and transferred into tubes without anticoagulant. Blood samples were centrifuged at $3500 \mathrm{rpm}$ for $15 \mathrm{~min}$, at $4{ }^{\circ} \mathrm{C}$, and the serum was separated into $1.5 \mathrm{~mL}$ aliquots and stored in a freezer at $-80^{\circ} \mathrm{C}$ until analysis. Serum total cholesterol (TC), HDL cholesterol, LDL cholesterol, and triglyceride (TG) concentrations were determined using LABTEST kits (Lagoa Santa, Minas Gerais, Brazil), according to the manufacturer's instructions. The analysis was carried out at the Laboratory of Research on Clinical Biochemistry of the UFRN, using the biochemical analyzer LABMAX PLENNO (Labtest, Lagoa Santa, Minas Gerais, Brazil).

\section{Statistical analysis}

The descriptive analysis was performed using percentage, mean, and standard deviation, according to the data type. The $\mathrm{t}$-test was used to compare the pre-post intervention means (curcumin and placebo). To verify differences between pre-placebo and pre-curcumin, as well as post-placebo and post-curcumin, the paired t-test was used. Statistical analysis was performed using IBM SPSS Statistics v.22 and a significance level of 5\% was adopted for all analyses.

\section{Results}

Initially, 30 participants were enrolled, however 9 abandoned the protocol and 1 was excluded as he stopped using ART. Thus, 20 individuals completed the study. Overall, $12(60 \%)$ were male and $8(40 \%)$ female, with a mean age of 45.5 (9.7) years. The sample were heterogeneous with respect to HIV infection, demographic and lifestyle variables (Table 1).

The participants' food intake remained constant throughout the study period and both the EG and CG consumed more unprocessed or minimally processed foods (Table 2). No change was observed in the respiratory quotient or body composition of subjects after curcumin supplementation. However, TG levels increased after curcumin supplementation in the EG (Table 3). No side effects were observed during curcumin supplementation. There was no significant difference in the baseline values (pre) between EG and CG.

\section{Discussion}

This study was the first clinical trial to investigate the influence of curcumin supplementation on metabolic and lipid parameters in people living with HIV/AIDS. Both experimental and control groups presented similar characteristics regarding dietary intake, body composition, substrate oxidation, and blood lipid profile at baseline. The main finding was the increase in serum TG levels after curcumin supplementation. None of the other parameters studied changed after the intervention.

Curcumin supplementation did not alter the energy substrate oxidation at rest or body composition of participants. Also, as shown in Table 3, the time effect was not significant, indicating that 30 days of curcumin supplementation was not sufficient to influence these parameters in the population studied. These findings may be associated with the complex mechanisms of HIV lipodystrophy. High carbohydrate oxidation at rest, also observed in other studies, is related to complex mechanisms such as mitochondrial dysfunction and impairment of fatty acid transport proteins [27, 28]. Substrate oxidation is influenced by central fat accumulation, a common feature of lipohypertrophy, which is hard to reverse, even with exercise or dietary interventions [29, 30]. Also, the precision error of the bone tissue can reach up to $2 \%$ and, in soft tissues, the standard error is based on the assumption of a constant hydration status of these tissues [31].

In the present study, the increase in serum TG levels after curcumin supplementation was contrary to previous studies which evaluated the effect of curcumin on the lipid profile of healthy individuals [32] and patients with chronic diseases, who have an inflammatory but not infectious profile, such as obesity [33], metabolic syndrome [34], and type 2 diabetes mellitus [35]. In these studies, the TG levels decreased after curcumin supplementation. Previous studies with people living with HIV/AIDS have shown only beneficial effects of curcumin supplementation on diarrhea [36], viral replication [37], and inflammation [38].

Only one clinical trial with elderly subjects found that curcumin supplementation did not significantly change serum TC, LDL, HDL, and TG levels over time. Interestingly, the authors observed that concentrations of plasma curcumin and serum cholesterol were positively correlated [39]. Some authors state that the curcumin effect in lowering TC and TG may be more efficient in cases of concomitant high fat diet [15]. Considering this fact, it is important to highlight that in the present study 
Table 1 Clinical and socioeconomic aspects of people living with HIV/AIDS

\begin{tabular}{|c|c|c|c|}
\hline Variables & Categories & $\begin{array}{l}\text { Frequency } \\
(n=20)\end{array}$ & $\begin{array}{l}\text { Percentage } \\
(\%)\end{array}$ \\
\hline Time of HIV diagnosis & $\begin{array}{l}\text { Up to } 57 \text { months } \\
58 \text { to } 126 \text { months } \\
127 \text { to } 183 \text { months } \\
184 \text { to } 288 \text { months }\end{array}$ & $\begin{array}{l}5 \\
5 \\
5 \\
5\end{array}$ & $\begin{array}{l}25 \\
25 \\
25 \\
25\end{array}$ \\
\hline Time on Antiretroviral Therapy & $\begin{array}{l}\text { Up to } 57 \text { months } \\
58 \text { to } 120 \text { months } \\
121 \text { to } 180 \text { months } \\
181 \text { to } 240 \text { months }\end{array}$ & $\begin{array}{l}5 \\
6 \\
5 \\
4\end{array}$ & $\begin{array}{l}25 \\
30 \\
25 \\
20\end{array}$ \\
\hline Combination Antiretroviral Therapy & $\begin{array}{l}\text { NRTI + NtRTI + NNRTI } \\
\text { NRTI + NNRTI } \\
\text { PI + NRTI + NtRTI } \\
P I+N R T I \\
\text { PI + NRTI + NNRTI } \\
\text { NRTI + PI + II }\end{array}$ & $\begin{array}{l}7 \\
6 \\
2 \\
3 \\
1 \\
1\end{array}$ & $\begin{array}{l}35 \\
30 \\
10 \\
15 \\
5 \\
5\end{array}$ \\
\hline Comorbidities & $\begin{array}{l}\text { None } \\
\text { Hypertension } \\
\text { Depression } \\
\text { Type } 2 \text { diabetes } \\
\text { Type } 2 \text { diabetes, hypertension, depression, and osteoporosis }\end{array}$ & $\begin{array}{l}14 \\
3 \\
1 \\
1 \\
1\end{array}$ & $\begin{array}{l}70 \\
15 \\
5 \\
5 \\
5\end{array}$ \\
\hline Work & $\begin{array}{l}\text { Yes } \\
\text { No }\end{array}$ & $\begin{array}{l}7 \\
13\end{array}$ & $\begin{array}{l}35 \\
65\end{array}$ \\
\hline Alcohol consumption & $\begin{array}{l}\text { Yes } \\
\text { No }\end{array}$ & $\begin{array}{l}10 \\
10\end{array}$ & $\begin{array}{l}50 \\
50\end{array}$ \\
\hline Smoke & $\begin{array}{l}\text { Yes } \\
\text { No }\end{array}$ & $\begin{array}{l}3 \\
17\end{array}$ & $\begin{array}{l}15 \\
85\end{array}$ \\
\hline Schooling & $\begin{array}{l}\text { Middle school } \\
\text { High School } \\
\text { College }\end{array}$ & $\begin{array}{l}4 \\
12 \\
4\end{array}$ & $\begin{array}{l}20 \\
60 \\
20\end{array}$ \\
\hline Family income $e^{a}$ & $\begin{array}{l}\text { Up to } 1 \text { Brazilian salary } \\
\text { Up to } 2 \text { Brazilian salary } \\
\text { Up to } 3 \text { Brazilian salary } \\
\text { Up to } 4 \text { Brazilian salary }\end{array}$ & $\begin{array}{l}6 \\
6 \\
4 \\
4\end{array}$ & $\begin{array}{l}32 \\
3 \\
5 \\
26\end{array}$ \\
\hline
\end{tabular}

NRTI Nucleoside Reverse Transcriptase Inhibitor, NtRTI nucleotide reverse transcriptase inhibitors, NNRTI Non-nucleoside reverse transcriptase inhibitors, PI Protease inhibitors, II Integrase Inhibitor

${ }^{\text {a}}$ Family income expressed in Brazilian salary (1 Brazilian salary corresponds approximately to US\$260.00)

the participants met the daily recommendation for fat intake and none of them had a high fat diet.

However, it is possible that the increase in serum TG levels found in the experimental group of this study may have been partially influenced by diet. Although there is no gold standard method for assessing dietary intake, it is not a new fact that dietary composition influences serum lipids and lipoproteins [40]. Previous studies evaluating the effect of curcumin on the serum lipid profile [32-35] did not control food consumption. In the present study, in addition to the advice to maintain habitual eating habits, food consumption was also investigated. Although no significant differences in the dietary intake of the participants was observed, the high standard deviation of the results confers a certain variation in energy and macronutrient intake, which may have influenced the results regarding the lipid profile, especially serum TG levels. For example, the high intake of simple carbohydrates raises blood concentrations of TG. This phenomenon is known as carbohydrate-induced hypertriglyceridemia [41]. Moreover, individual genetic polymorphisms linked to the lipid metabolism, an aspect not investigated in the present study, are influenced by dietary intake and can modulate the lipid profile differently in people [42-44].

In addition, the participants of this study were physically active and previously enrolled in a 6-month exercise plan. This fact may have affected the effect of curcumin supplementation on the serum lipid profile, since physical exercise promotes several metabolic adaptations which contribute to preservation of lean mass and improvement in insulin sensitivity and lipid profile [45]. Perhaps curcumin supplementation may generate more positive results in the lipid profile of sedentary people living with HIV/AIDS.

The increase in serum TG levels after curcumin supplementation observed in our study also demonstrates the complexity of the metabolic alterations developed by patients with HIV under ART. These metabolic changes have a multifactorial etiology and their pathophysiological 
Table 2 Dietary intake of people living with HIV/AIDS

\begin{tabular}{|c|c|c|c|c|c|c|c|c|}
\hline & \multicolumn{2}{|c|}{$\begin{array}{l}\text { Experimental Group } \\
(n=20)\end{array}$} & \multicolumn{2}{|l|}{$P$ value } & \multicolumn{2}{|l|}{$\begin{array}{l}\text { Control Group } \\
(n=20)\end{array}$} & \multicolumn{2}{|l|}{$P$ value } \\
\hline & Pre & Post & Curcumin Effect & $\overline{T i m e}$ Effect (Pre) & Pre & Post & Placebo Effect & Time Effect (Post) \\
\hline \multicolumn{9}{|l|}{24 h-Food Recall } \\
\hline Energy (Kcal/day) & $1837.1(717.6)$ & $1782.1(739.3)$ & 0.805 & 0.730 & $1736.5(925.0)$ & $1680.6(580.4)$ & 0.785 & 0.632 \\
\hline Protein (g/kg/day) & $1.3(0.6)$ & $1.4(0.7)$ & 0.972 & 0.615 & $1.5(0.7)$ & $1.2(0.7)$ & 0,216 & 0.701 \\
\hline Protein (\%) ${ }^{a}$ & $19.4(5.6)$ & $19.9(6.1)$ & 0.741 & 0.172 & $21.8(5.5)$ & $19.1(6.8)$ & 0.268 & 0.701 \\
\hline Carbohydrate (\%) ${ }^{\mathrm{a}}$ & $54.9(12.1)$ & $53.5(11.2)$ & 0.653 & 0.666 & $56.5(9.2)$ & $58.2(8.3)$ & 0.539 & 0.143 \\
\hline Lipid $(\%)^{a}$ & $25.7(9.3)$ & $26.6(7.0)$ & 0.692 & 0.139 & $21.7(7.0)$ & $22.7(7.5)$ & 0.602 & 0.100 \\
\hline Saturated Fat Acid (\%) & $7.6(4.2)$ & $9.3(2.9)$ & 0.113 & 0.961 & $7.6(3.3)$ & $7.3(3.4)$ & 0.760 & 0.055 \\
\hline Cholesterol (g/day) & $306.2(146.5)$ & $383.3(290.6)$ & 0.346 & 0.585 & $346.5(293.0)$ & 306.5 (205.0) & 0.509 & 0.341 \\
\hline Fiber (g/day) & $22.4(15.3)$ & $21.7(8.6)$ & 0.846 & 0.947 & $22.7(12.0)$ & $23.3(9.4)$ & 0.828 & 0.596 \\
\hline \multicolumn{9}{|l|}{ Food Consumption Markers } \\
\hline Groups 1-5 & $55.0(13.0)$ & $56.3(13.9)$ & 0.663 & 0.897 & $55.7(20.6)$ & $54.6(15.6)$ & 0.761 & 0.715 \\
\hline Groups 6-10 & $18.9(12.0)$ & $14.6(11.6)$ & 0.188 & 0.349 & $15.4(10.8)$ & $16.4(11.9)$ & 0.731 & 0.620 \\
\hline
\end{tabular}

All values are expressed as mean (standard deviation). ${ }^{a}$ Results in percentage of energy contribution

mechanisms are not fully understood. Feeney and Mallon [46] discussed the overall effects of ART on lipid profiles. The majority of antiretroviral drugs present dyslipidemic properties. Considering that all participants from both the experimental and control groups in this study were exposed to a combination of ART, we assume that the effect of the antiretroviral drugs used may have masked the potential benefits of the curcumin. The metabolic abnormalities related to ART found in HIV-infected patients are complex and encompass several metabolic pathways and mechanisms [47-50].

Clinical studies [32-35] and reviews $[8,15]$ have demonstrated the lipid-lowering effect of curcumin.
However, this evidence is questionable in some metaanalyses [4, 51]. Apparently, this effect can be concealed by heterogeneous populations and a lack of methodological standardization [4]. In addition, the therapeutic efficacy of curcumin is still limited due to characteristics such as poor water solubility, low bioavailability, chemical instability, photodegradation, rapid metabolism, and a short half-life. Evidence about this bioactive compound has stimulated the development of new pharmaceutical formulas and new delivery systems which may improve the efficacy of curcumin [52].

Our study had some limitations. The immunological, virological, hormonal, and genetic aspects were not

Table 3 Effect of curcumin supplementation on lipid profile, respiratory quotient, and body composition in people living with HIV/ AIDS

\begin{tabular}{|c|c|c|c|c|c|c|c|c|}
\hline & \multicolumn{2}{|c|}{$\begin{array}{l}\text { Experimental Group } \\
(n=20)\end{array}$} & \multicolumn{2}{|l|}{$P$ value } & \multicolumn{2}{|c|}{$\begin{array}{l}\text { Control Group } \\
(n=20)\end{array}$} & \multicolumn{2}{|l|}{$P$ value } \\
\hline & Pre & Post & $\begin{array}{l}\text { Curcumin } \\
\text { Effect }\end{array}$ & $\begin{array}{l}\text { Time Effect } \\
\text { (Pre) }\end{array}$ & Pre & Post & $\begin{array}{l}\text { Placebo } \\
\text { Effect }\end{array}$ & $\begin{array}{l}\text { Time Effect } \\
\text { (Post) }\end{array}$ \\
\hline $\begin{array}{l}\text { Total Cholesterol (mg/ } \\
\mathrm{dL} \text { ) }\end{array}$ & $197.1(39.9)$ & $206.9(52.4)$ & 0.067 & 0.698 & $203.0(55.2)$ & $204.1(46.1)$ & 0.845 & 0.856 \\
\hline LDL (mg/dL) & $124.6(30.2)$ & $126.1(39.5)$ & 0.781 & 0.681 & 120.9 (33.8) & $128.6(33.6)$ & 0.318 & 0.814 \\
\hline $\mathrm{HDL}(\mathrm{mg} / \mathrm{dL})$ & $37.4(11.9)$ & $35.3(13.8)$ & 0.355 & 0.723 & $39.1(17.6)$ & $35.1(13.2)$ & 0.257 & 0.981 \\
\hline Triglycerides (mg/dL) & $\begin{array}{l}182.1 \\
(131.9)\end{array}$ & $\begin{array}{l}219.0 \\
(140.3)\end{array}$ & $0.004^{*}$ & 0.737 & $\begin{array}{l}195.9 \\
(125.7)\end{array}$ & $\begin{array}{l}198.9 \\
(127.0)\end{array}$ & 0.799 & 0.638 \\
\hline $\begin{array}{l}\text { Respiratory Quotient } \\
\text { (RQ) }\end{array}$ & $0.9(0.1)$ & $0.8(0.1)$ & 0.728 & 0.426 & $0.8(0.0)$ & $0.8(0.1)$ & 0.774 & 0.579 \\
\hline Total Body Fat (\%) & $26.9(7.3)$ & $26.8(7.4)$ & 0.785 & 0.973 & $29.3(9.2)$ & $28.8(9.0)$ & $0.035^{*}$ & 0.612 \\
\hline Arms Fat (\%) & $23.0(8.7)$ & $22.7(9.2)$ & 0.467 & 0.860 & $26.1(11.3)$ & $25.9(11.6)$ & 0.643 & 0.468 \\
\hline Legs Fat (\%) & $22.7(8.7)$ & $23.0(9.1)$ & 0.233 & 0.834 & $24.8(10.2)$ & $24.6(9.8)$ & 0.536 & 0.702 \\
\hline Trunk Fat (\%) & $31.1(9.0)$ & $30.2(8.7)$ & 0.338 & 0.781 & $33.6(10.3)$ & $32.7(10.2)$ & $0.019^{*}$ & 0.575 \\
\hline BMI $\left(\mathrm{kg} / \mathrm{m}^{2}\right)$ & $23.7(2.1)$ & $23.7(2.2)$ & 0.832 & 0.934 & $25.0(5.4)$ & $25.0(5.5)$ & 0.653 & 0.426 \\
\hline
\end{tabular}

All values are expressed as mean (standard deviation). LDL LDL-cholesterol, HDL HDL-cholesterol, BMI Body Mass Index. ${ }^{*}$ Significant values $(P<0.05)$ 
considered or controlled in this study. Besides that, our study had a limited number of participants. However, the cross over nature of the analysis allowed us to conclude the increasing of triglycerides found in this cohort is worthy of further investigation.

\section{Conclusion}

Curcumin supplementation did not alter the energy substrate oxidation at rest, nor the body composition of physically active people living with HIV/AIDS under ART but did increase serum TG levels in this population. Further studies, with a larger sample cohort, different curcumin dosages, and longer intervention times are needed to validate current observations. In addition, the influence of physical activity, dietary intake, and genetic polymorphisms must be considered in future studies to better understand the impact of curcumin supplementation on the lipid profile of people living with HIV/AIDS, under antiretroviral therapy.

\section{Additional file}

Additional file 1: Evaluation form. (PDF $231 \mathrm{~kb}$ )

\section{Abbreviations}

AIDS: Acquired immune deficiency syndrome; ART: Antiretroviral therapy; EG: Experimental group; CG: Control group; HDL: High-density lipoprotein; HIV: Human immunodeficiency virus; LDL: Low-density lipoprotein; TC: Total cholesterol; TG: Triglycerides

\section{Acknowledgements}

We thank all members of the Viver+ Program for their invaluable assistance.

\section{Authors' contributions}

TALS was the major contributor of the manuscript and participated in all steps. DCM, GCBS, RCSCM, JSA collected and interpreted the data. JAM performed the statistical analysis. MAGU performed the biochemical analysis and contributed in the manuscript writing. TALS, RVTS, LLL and PMSD designed the research project, interpreted the data, and wrote the manuscript. RMVM made substantial contributions to the data interpretation and have substantively revised the manuscript. All authors read and approved the final manuscript.

\section{Funding}

This work was supported in part by the FINEP (Funding Authority for Studies and Projects), grant number 0187/12, which covered the acquisition of the DXA equipment and the biochemical analyses.

\section{Availability of data and materials}

The datasets used are available from the corresponding author on reasonable request.

\section{Ethics approval and consent to participate}

The protocol was reviewed and approved by the Human Research Ethics Committee of the Federal University of Rio Grande do Norte, Brazil (CAAE 42950214.7.0000.5537), and it was registered in Clinical Trials (NCT03141918), available at https://clinicaltrials.gov/ct2/show/NCT03141918. Written consent was obtained from all participants.

\section{Consent for publication}

Written consent to publish the information and data of the participants was obtained.

\section{Competing interests}

The authors declare that they have no competing interests.

\section{Author details}

${ }^{1}$ Postgraduate Program in Health Science, Federal University of Rio Grande do Norte, Av. Nilo Peçanha 620, Petropolis, Natal, RN 59012-300, Brazil. ${ }^{2}$ Department of Physical Education, Federal University of Rio Grande do Norte, Campus Universitario, Lagoa Nova, Natal, RN 59078-900, Brazil. ${ }^{3}$ Department of Nutrition, Federal University of Rio Grande do Norte, Campus Universitario, Lagoa Nova, Natal, RN 59078-900, Brazil. ${ }^{4}$ Department of Clinical and Toxicological Analyses, Centro de Ciencias da Saude, Petropolis, Natal, RN 59012-300, Brazil. ${ }^{5}$ Bioscience Department, Federal University of Sao Paulo, UNIFESP, Avenida Ana Costa, 96, Vila Matias, Santos, SP 11060-001, Brazil. ${ }^{6}$ Centro Universitário do Rio Grande do Norte, UNIRN, Rua Prefeita Eliane Barros, 2000, Tirol, Natal, RN 59014-545, Brazil.

Received: 14 June 2018 Accepted: 26 July 2019

Published online: 06 August 2019

\section{References}

1. Maggi P, Di Biagio A, Rusconi S, Cicalini S, D’Abbraccio M, d'Ettorre G, et al. Cardiovascular risk and dyslipidemia among persons living with HIV: a review. BMC Infect Dis. 2017;17(1):551

2. Cunha J, Maselli LMF, Stern ACB, Spada C, Bydlowski. Impact of antiretroviral therapy on lipid metabolism of human immunodeficiency virus-infected patients: old and new drugs. World J Virol. 2015:4(2):56-77.

3. Silva TA, Barboza RR, Andrade RD, Medeiros RC, Medeiros JA, Souza HA, et al. Relationship between dietary intake and use of protease inhibitors with anthropometric and biochemical parameters of lipodystrophy in people living with hiv. Nutricion hospitalaria. 2014;30(4):935-40.

4. Sahebkar A. A systematic review and meta-analysis of randomized controlled trials investigating the effects of curcumin on blood lipid levels. Clin Nutr. 2014;33(3):406-14.

5. Calza L, Colangeli V, Manfredi R, Bon I, Re MC, Viale P. Clinical management of dyslipidaemia associated with combination antiretroviral therapy in HIVinfected patients. J Antimicrob Chemother. 2016;71(6):1451-65.

6. Atkinson EC, Hadigan C. Management of dyslipidemia in HIV infection. Clinical Lipidology. 2012;7(6):603-6.

7. Chauvin B, Drouot S, Barrail-Tran A, Taburet AM. Drug-drug interactions between HMG-CoA reductase inhibitors (statins) and antiviral protease inhibitors. Clin Pharmacokinet. 2013;52(10):815-31.

8. Gupta SC, Patchva S, Koh W, Aggarwal BB. Discovery of curcumin, a component of golden spice, and its miraculous biological activities. Clin Exp Pharmacol Physiol. 2012:39(3):283-99.

9. Prasad S, Tyagi AK. Curcumin and its analogues: a potential natural compound against HIV infection and AIDS. Food Funct. 2015:6(11):3412-9.

10. Ali A, Banerjea AC. Curcumin inhibits HIV-1 by promoting tat protein degradation. Sci Rep. 2016:6:27539.

11. Tabrizi R, Vakili S, Akbari M, Mirhosseini N, Lankarani KB, Rahimi M, et al. The effects of curcumin-containing supplements on biomarkers of inflammation and oxidative stress: A systematic review and meta-analysis of randomized controlled trials. Phytother Res. 2019;33(2):253-262.

12. Kasi PD, Tamilselvam R, Skalicka-Woźniak K, Nabavi SF, Daglia M, Bishayee A et al. Molecular targets of curcumin for cancer therapy: an updated review. Tumor Biol. 2016:37(10):13017-28.

13. Parsamanesh N, Moossavi M, Bahrami A, Butler AE, Sahebkar A. Therapeutic potential of curcumin in diabetic complications. Pharmacol Res. 2018;136:181-93.

14. Sirtori CR, Pavanello C, Calabresi L, Ruscica M. Nutraceutical approaches to metabolic syndrome. Ann Med. 2017:49(8):678-97.

15. Panahi Y, Ahmadi Y, Teymouri M, Johnston TP, Sahebkar A. Curcumin as a potential candidate for treating hyperlipidemia: a review of cellular and metabolic mechanisms. J Cell Physiol. 2018;233(1):141-52.

16. Cavenaghi FM, Bataglion CAN, Paula PC, Motta ACF, Komesu MC. Protease inhibitor and metabolic alteration. Int J Morphol. 2012;30(2):439-44.

17. Abrahams Z, Levitt N, Lesosky M, Maartens G, Dave J. Changes in body fat distribution on dual-energy $\mathrm{X}$-ray absorptiometry in black south africans starting first-line antiretroviral therapy. AIDS Patient Care STDs. 2016;30(10): 455-62.

18. Paula AA, Falcao MC, Pacheco AG. Metabolic syndrome in HIV-infected individuals: underlying mechanisms and epidemiological aspects. AIDS Res Ther. 2013;10(1):32. 
19. Jager R, Lowery RP, Calvanese AV, Joy JM, Purpura M, Wilson JM. Comparative absorption of curcumin formulations. Nutr J. 2014;13:11.

20. American College of Sports Medicine. ACSM's health-related physical fitness assessment manual. 5th ed: Wolters Kluwer; 2018.

21. Matsudo S, Araujo T, Matsudo V, Andrade D, Andrade E, Oliveira LC, et al. Questionário Internacional de Atividade Física (Ipaq): Estupo de Validade e Reprodutibilidade no Brasil. Revista Brasileira de Atividade Física \& Saúde. 2001;6(2):5-18.

22. Borg G. Escalas de Borg para a Dor e o Esforço Percebido. São Paulo: Manole; 2000.

23. Robertson RJ, Goss FL, Rutkowski J, Lenz B, Dixon C, Timmer J, et al. Concurrent validation of the OMNI perceived exertion scale for resistance exercise. Med Sci Sports Exerc. 2003;35(2):333-41.

24. Thompson FE, Byers T. Dietary assessment resource manual. J Nutr. 1994; 124(Suppl 11):2245-317.

25. Brasil. Ministério da Saúde. Secretaria de Atenção à Saúde. Departamento de Atenção Básica. Protocolos do Sistema de Vigilância Alimentar e Nutricional - SISVAN na assistência à saúde / Ministério da Saúde, Secretaria de Atenção à Saúde. Departamento de Atenção Básica. Brasília: Ministério da Saúde, 2008.

26. Fornés NS, Martins IS, Velásquez-Meléndez G, Latorre MRDO. Consumption scores and serum lipids levels in the population of São Paulo, Brazil. Rev Saude Publica. 2002;36(1):12-8.

27. Kosmiski L, Kuritzkes D, Hamilton J, Sharp T, Lichtenstien K, Hill J, et al. Fat distribution is altered in HIV-infected men without clinical evidence of the HIV lipodystrophy syndrome. HIV Med. 2003;4(3):235-40.

28. Vassimon HS, Paula FJ, Machado AA, Monteiro JP, Jordao Jr. AA. Hypermetabolism and altered substrate oxidation in HIV-infected patients with lipodystrophy. Nutrition 2012;28(9):912-916.

29. Falutz J. Management of fat accumulation in patients with HIV infection. Current HIV/AIDS reports. 2011:8(3):200-8.

30. Paes LS, Borges JP, Santos FM, Oliveira TP, Dupin JG, Harris EA, et al. Effects of a 2-year supervised exercise program upon the body composition and muscular performance of HIV-infected patients. The Open AIDS J. 2015;9:808.

31. Laskey MA. Dual-energy X-ray absorptiometry and body composition. Nutrition. 1996;12(1):45-51.

32. DiSilvestro RA, Joseph E, Zhao S, Bomser J. Diverse effects of a low dose supplement of lipidated curcumin in healthy middle aged people. Nutr J. 2012;11:79.

33. Mohammadi A, Sahebkar A, Iranshahi M, Amini M, Khojasteh R, GhayourMobarhan $M$, et al. Effects of supplementation with curcuminoids on dyslipidemia in obese patients: a randomized crossover trial. Phytother Res. 2013;27(3):374-9.

34. Yang YS, Su YF, Yang HW, Lee YH, Chou Jl, Ueng KC. Lipid-lowering effects of curcumin in patients with metabolic syndrome: a randomized, doubleblind, placebo-controlled trial. Phytother Res. 2014;28(12):1770-7.

35. Na LX, Li Y, Pan HZ, Zhou XL, Sun DJ, Meng M, et al. Curcuminoids exert glucose-lowering effect in type 2 diabetes by decreasing serum free fatty acids: a double-blind, placebo-controlled trial. Mol Nutr Food Res. 2013; 57(9):1569-77.

36. Conteas CN, Panossian AM, Tran T, Singh HM. Treatment of HIV-associated diarrhea with curcumin. Dig Dis Sci. 2009;54(10):2188-91.

37. Gandapu U, Chaitanya RK, Kishore G, Reddy RC, Kondapi AK. Curcuminloaded apotransferrin nanoparticles provide efficient cellular uptake and effectively inhibit HIV-1 replication in vitro. PLoS One. 2011;6(8):e23388.

38. Ferreira VH, Nazli A, Dizzell SE, Mueller K, Kaushic C. The anti-inflammatory activity of curcumin protects the genital mucosal epithelial barrier from disruption and blocks replication of HIV-1 and HSV-2. PLoS One. 2015;10(4): e0124903.

39. Baum L, Cheung SK, Mok VC, Lam LC, Leung VP, Hui E, et al. Curcumin effects on blood lipid profile in a 6-month human study. Pharmacol Res. 2007:56(6):509-14.

40. Grundy SM, Denke MA. Dietary influences on serum lipids and lipoproteins. J Lipid Res. 1990;31(7):1149-72.

41. Parks EJ. Effect of dietary carbohydrate on triglyceride metabolism in humans. J Nutr. 2001;131(10):2772S-4S.

42. Garcia-Rios A, Perez-Martinez P, Delgado-Lista L-MJ, Perez-Jimenez F. Nutrigenetics of the lipoprotein metabolism. Mol Nutr Food Res. 2012;56(1): 171-83.
43. Andrade FM, Bulhoes AC, Maluf SW, Schuch JB, Voigt F, Lucatelli JF, et al. The influence of nutrigenetics on the lipid profile: interaction between genes and dietary habits. Biochem Genet. 2010;48(3-4):342-55.

44. Pollin TI, Quartuccio M. What we know about diet, genes, and dyslipidemia: is there potential for translation? Curr Nutr Rep. 2013;2(4):236-42.

45. Peres SB, Moraes SM, Costa CE, Brito LC, Takada J, Andreotti S, et al. Endurance exercise training increases insulin responsiveness in isolated adipocytes through IRS/PI3-kinase/Akt pathway. J Appl Physiol (1985). 2005; 98(3):1037-43.

46. Feeney ER, Mallon PW. HIV and HAART-associated dyslipidemia. Open Cardiovasc Med J. 2011;5:49-63.

47. Grunfeld C. Dyslipidemia and its treatment in HIV infection. Top HIV Med. 2010;18(3):112-8.

48. Fisher SD, Miller TL, Lipshultz SE. Impact of HIV and highly active antiretroviral therapy on leukocyte adhesion molecules, arterial inflammation, dyslipidemia, and atherosclerosis. Atherosclerosis. 2006;185(1):1-11.

49. Hung YP, Lee NY, Lin SH, Chang HC, Wu CJ, Chang CM, et al. Effects of PPARy and RBP4 gene variants on metabolic syndrome in HIV-infected patients with anti-retroviral therapy. PLoS One. 2012;7(11):e49102.

50. Domingo P, Gutierrez MM, Gallego-Escuredo JM, Torres F, Mateo GM, Villarrova J, et al. Effects of switching from stavudine to raltegravir on subcutaneous adipose tissue in HIV-infected patients with HIV/HAARTassociated lipodystrophy syndrome (HALS). A clinical and molecular study. PLoS One. 2014;9(2):e89088.

51. Qin S, Huang L, Gong J, Shen S, Huang J, Ren H, et al. Efficacy and safety of turmeric and curcumin in lowering blood lipid levels in patients with cardiovascular risk factors: a meta-analysis of randomized controlled trials. Nutr J. 2017;16(1):68.

52. Hussain Z, Thu HE, Amjad MW, Hussain F, Ahmed TA, Khan S. Exploring recent developments to improve antioxidant, anti-inflammatory and antimicrobial efficacy of curcumin: a review of new trends and future perspectives. Mater Sci Eng C Mater Biol Appl. 2017;77:1316-2.

\section{Publisher's Note}

Springer Nature remains neutral with regard to jurisdictional claims in published maps and institutional affiliations.

Ready to submit your research? Choose BMC and benefit from:

- fast, convenient online submission

- thorough peer review by experienced researchers in your field

- rapid publication on acceptance

- support for research data, including large and complex data types

- gold Open Access which fosters wider collaboration and increased citations

- maximum visibility for your research: over $100 \mathrm{M}$ website views per year

At $\mathrm{BMC}$, research is always in progress.

Learn more biomedcentral.com/submissions 